\title{
Prospective Study of Nutritional Factors, Blood Pressure, and Hypertension Among US Women
}

\section{Citation}

Ascherio, Alberto, Charles Hennekens, Walter C. Willett, Frank Sacks, Bernard Rosner, JoAnn Manson, Jacqueline Witteman, and Meir J. Stampfer. 1996. "Prospective Study of Nutritional Factors, Blood Pressure, and Hypertension Among US Women." Hypertension 27 (5): 1065-72. https://doi.org/10.1161/01.hyp.27.5.1065.

\section{Permanent link}

http://nrs.harvard.edu/urn-3:HUL.InstRepos:41292992

\section{Terms of Use}

This article was downloaded from Harvard University's DASH repository, WARNING: This file should NOT have been available for downloading from Harvard University's DASH repository.

\section{Share Your Story}

The Harvard community has made this article openly available.

Please share how this access benefits you. Submit a story.

Accessibility 


\title{
A Prospective Study of Nutritional Factors and Hypertension Among US Women
}

\author{
Jacqueline C.M. Witteman, MS, Walter C. Willett, MD, Meir J. Stampfer, MD, \\ Graham A. Colditz, MB, BS, Frank M. Sacks, MD, Frank E. Speizer, MD, \\ Bernard Rosner, $\mathrm{PhD}$, and Charles H. Hennekens, MD
}

\begin{abstract}
The relation of various nutritional factors with hypertension was examined prospectively among 58,218 predominantly white US female registered nurses, aged 34-59 years. In 1980, all women completed an independently validated dietary questionnaire. During 4 years of follow-up, 3,275 women reported a diagnosis of hypertension; the validity of the self-report was shown in a subsample. Age, relative weight, and alcohol consumption were the strongest predictors for the development of hypertension. Dietary calcium and magnesium had independent and significant inverse associations with hypertension. For women with a calcium intake of at least $800 \mathrm{mg} / \mathrm{day}$, the relative risk of hypertension was 0.78 (95\% confidence interval, $0.69-0.88)$ when compared with an intake of less than $400 \mathrm{mg} / \mathrm{day}$. The relative risk for magnesium intake of $300 \mathrm{mg} / \mathrm{day}$ or more compared with an intake of less than $200 \mathrm{mg} / \mathrm{day}$ was 0.77 (95\% confidence interval, 0.67-0.88). For women with high intakes of both calcium and magnesium compared with those having low intakes of both, the relative risk of hypertension was 0.65 (95\% confidence interval, 0.53-0.80). No independent associations with hypertension were observed for intakes of potassium, fiber, and saturated and polyunsaturated fatty acids. These prospective findings add to the growing evidence to support the need for randomized trials to determine whether there is a protective role of dietary calcium and magnesium in the regulation of blood pressure. (Circulation 1989;80:1320-1327)
\end{abstract}

$\mathrm{T}$

The search for nonpharmacologic approaches to prevent and control hypertension has led to interest in the effects of diet. For several decades, research has mainly focused on potentially adverse effects of excess sodium intake. ${ }^{1}$ Dietary potassium has been inversely related to blood pressure in some, ${ }^{2-4}$ but not all ${ }^{5,6}$ cross-sectional studies, and supplementation has yielded conflicting results in clinical trials. 7,8 Among other dietary constituents of protective effects, calcium, $, 3,4,6$ fiber, ${ }^{9}$

From the Department of Epidemiology (J.C.M.W.), Erasmus University School of Medicine, Rotterdam, The Netherlands; The Channing Laboratory (W.C.W., M.J.S., G.A.C., F.M.S., F.E.S., C.H.H.), Department of Medicine, Harvard Medical School and Brigham and Women's Hospital; Departments of Epidemiology and Nutrition (W.C.W.), Harvard School of Public Health; Department of Preventive Medicine (B.R., C.H.H.), Harvard Medical School, Boston, Massachusetts.

Supported by research grants from the National Institutes of Health (CA-40935, HL-24074, HL-34594). J.C.M.W. was supported by a research grant from the Dutch Heart Foundation (The Hague). F.M.S. is an Established Investigator of the American Heart Association.

Address for correspondence: Walter C. Willett, MD, Brigham and Women's Hospital, Department of Medicine, Channing Laboratory, 180 Longwood Avenue, Boston, MA 02115.

Received January 23, 1989; revision accepted July 13, 1989. and polyunsaturated fatty acids ${ }^{10}$ have been suggested. Positive associations have been observed between alcohol intake and blood pressure. ${ }^{11}$ The relation of dietary magnesium with blood pressure has received much less attention.

With few exceptions, ${ }^{12,13}$ epidemiologic studies of diet and blood pressure have been cross-sectional ${ }^{2-6,9,14}$ rather than prospective. Although most studies excluded subjects on a prescribed diet, these studies still might have included hypertensive subjects who changed their diet after the diagnosis. Furthermore, most studies used a 24hour recall to measure diet, ${ }^{3-5,9,14}$ which is generally a poor reflection of the usual intake of an individual. ${ }^{15}$

In 1980, information on dietary intake over the preceding year was collected from a large cohort of US women. In the present study, we examine nutrient intake in relation to the development of hypertension during 4 years of follow-up. In addition to providing a very large study population, the potential for dietary change secondary to the diagnosis of high blood pressure is minimized in this study because of the prospective design and exclusion of persons with known hypertension at baseline. 


\begin{abstract}
Methods
Nurses' Health Study

The Nurses' Health Study is a prospective investigation of major diseases among a cohort of female registered nurses living in 11 states in the United States. In 1976, 121,700 women (98\% white) aged $30-55$ years completed mailed questionnaires regarding risk factors for cardiovascular diseases and cancer ${ }^{16}$ as well as other major health conditions. Follow-up questionnaires are sent biennially to update information.
\end{abstract}

\section{Measurement of Dietary Intake}

In 1980, the mailing to participants included a semiquantitative food frequency questionnaire that contained 61 food items, including alcoholic beverages. For each food, a commonly used portion size was specified, and participants were asked about their average frequency of use during the last year. Nine possible responses were provided, ranging from never to six or more times a day. Intake scores for different nutrients were computed by multiplying the reported frequency of each food by the nutrient content of the specified portion; the frequency of any food with a missing value was counted as zero. The nutrients examined in this study were total energy, dietary fiber, total fat, saturated fat, linoleic acid, trans-unsaturated fatty acids, calcium, magnesium, potassium, and alcohol. Calcium and magnesium intake were calculated only from food sources because information on their supplementation was not collected in 1980 . We did not attempt to measure sodium intake in this study because of the relatively large and variable contribution of salt added to processed food, in cooking, and at the table. Extensive data on the reproducibility and validity of the food frequency questionnaire have been published elsewhere. ${ }^{17-19}$ Nutrient intakes assessed by the questionnaire are reasonably reproducible, with correlations for intervals of 3-9 months being in the range of $0.5-0.7$ for most nutrients. When compared with multiple weeks of dietary records, correlations have ranged between 0.5 and 0.6 for most nutrients when adjusted for total caloric intake (see below).

\section{Diagnosis of Hypertension}

Blood pressure status was defined by selfreported responses to the questionnaires. In 1976, participants were asked whether or not they ever had a diagnosis of high blood pressure (excluding during pregnancy). On subsequent biennial questionnaires, we inquired whether subjects had been diagnosed as having high blood pressure during the previous 2 years and, if so, the date of diagnosis. The validity of self-reported diagnosis of hypertension was assessed in a separate study. ${ }^{20}$ Briefly, a random sample of 100 nurses reporting a diagnosis of high blood pressure on the 1982 questionnaire were contacted again in 1983 to obtain permission for review of their medical records. Records were obtained for 51 subjects. All had recorded values of blood pressure greater than $140 / 90 \mathrm{~mm} \mathrm{Hg}$, and for 39 women $(77 \%)$, blood pressure was greater than $160 / 95 \mathrm{~mm} \mathrm{Hg}$. To investigate the likelihood of false-negative responses, blood pressure was measured in an age-stratified sample of 194 nurses living in the greater Boston area. Among the 161 women without a previous self-report of high blood pressure, $7 \%$ had a blood pressure level higher than $140 / 90 \mathrm{~mm} \mathrm{Hg}$, but none of these women had a blood pressure greater than $160 / 95 \mathrm{~mm} \mathrm{Hg}$. Thus, the self-reported diagnosis of elevated blood pressure appeared to be a valid measure in this population of registered nurses.

\section{Population for Analysis}

A total of 98,462 women returned the 1980 Nurses' Health Study dietary questionnaire. Participants with 10 or more blank food items $(4 \%)$ or with an implausibly high or low total food score $(2.7 \%)$ were excluded. From the remaining women, we excluded those who reported one or more of the following diagnoses on the 1980 or previous questionnaires: high blood pressure $(18,818)$, myocardial infarction (611), angina pectoris $(1,545)$, diabetes mellitus $(2,202)$, and all cancers except nonmelanoma skin cancer $(3,646)$. Participants indicating on the 1980 questionnaire that they currently used antihypertensive medication $(10,433)$, were on a special diet $(15,006)$, or had been pregnant for at least 6 months since $1978(1,578)$ were also excluded. The total number of participants excluded for one or more reasons was 38,262 so that the baseline population consisted of 60,200 women.

Follow-up questionnaires were sent in 1982 and in 1984 to all study participants. The 1,982 nonrespondents to both follow-up questionnaires (3.3\%) were excluded, leaving 58,218 women for analysis. There were 3,275 incident cases of hypertension reported on the 1982 or 1984 questionnaire.

\section{Data Analysis}

Exposure status for all variables was defined by responses to the 1980 questionnaire. Nutrients were adjusted for total caloric intake as described elsewhere, ${ }^{17}$ by computing the difference between the observed nutrient intake and expected nutrient intake predicted by regressing the nutrient intakes for the whole population on their total energy intakes. Analyses of hypertension risk were based on 4-year cumulative incidence rates. For each calorie-adjusted nutrient, we specified five categories. Cutoff points were chosen before examining the association of diet with hypertension to provide similar increments in nutrient intake from one category to the next and to include a reasonable number of subjects in each category. The use of even-interval cutoff points has appeal in evaluating linear trends and in comparing different studies. Age-adjusted partial correlation coefficients were 


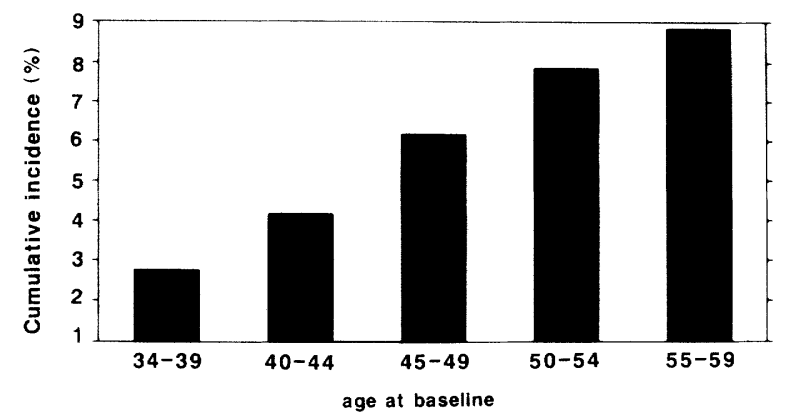

FIGURE 1. Bar graph of 4-year cumulative incidence of hypertension 5 by age, among the Nurses' Health Study cohort of 58,218 US women, 1980-1984.

calculated between pairs of exposure variables to evaluate potential confounding effects (this correlation matrix is available on request from the author). Multiple logistic regression analysis with categorical variables was used to control for confounding. Relative risks of hypertension with $95 \%$ confidence intervals were calculated by comparing each category of intake to the lowest category. Linear trends in risks over successive categories were evaluated by entering indicators for each categorical level of exposure, using the median values of each category. Relative risks were calculated within strata of other variables by combining the second with the third and the fourth with the fifth category of the exposure to obtain more statistically stable associations.

\section{Results}

The 4-year cumulative incidence of hypertension rose sharply with age from $2.8 \%$ for women aged 34-39 years to $8.9 \%$ for women aged 55-59 years (Figure 1). Quetelet's index and alcohol consumption were also strongly associated with an increasing risk of hypertension (Table 1). Nutrient intakes were only weakly correlated with Quetelet's index (all age-adjusted correlation coefficients less than $0.05)$ but were correlated more strongly with alcohol consumption ( $r$ up to 0.30 ). Therefore, we controlled for age, Quetelet's index, and alcohol consumption in all further analyses. Adjusted relative risks were only significant for intakes of calcium, magnesium, potassium, and fiber (Table 2). No effects were found for total and saturated fat, linoleic acid, and trans-unsaturated fatty acids (Table 3). Adjustment for smoking, menopausal status, and postmenopausal estrogen use did not alter the observed associations.

Relatively high correlations were observed between a number of different nutrients. Ageadjusted correlation coefficients for the nutrients presented in Table 1 varied widely and were 0.17 for calcium and fiber, 0.27 for magnesium and fiber, 0.53 for magnesium and calcium, and 0.69 for magnesium and potassium. When entered simultaneously in a multiple logistic model, only dietary calcium and magnesium were independently associated with risk of hypertension (Table 2). The associations of dietary potassium and fiber with risks of hypertension were practically eliminated after controlling for dietary calcium and magnesium (Table 2). The study was sufficiently large so that, even in the multivariate analyses, the confidence interval for potassium did not include any major association; for high dietary fiber intake $(>25 \mathrm{~g} /$ day), the data were still compatible with a modest protective effect, because the lower bound confidence interval was 0.71 .

We next examined dietary intakes of calcium and magnesium from different food sources. Dairy products accounted for $61 \%$ of the calcium intake; the main contributors to magnesium intake were fruits and vegetables $(27 \%)$, cereals $(17 \%)$, and dairy products $(13 \%)$. Calcium from both dairy and nondairy sources and magnesium intake from cereals and dairy foods, as well as from the remaining foods, were each independently associated with lower risks of hypertension (Table 4).

Associations of calcium and magnesium intake with hypertension were examined within categories of other variables that could modify the relation

TABLE 1. Relative Risks of Hypertension by Level of Quetelet's Index and Daily Intake of Alcohol

\begin{tabular}{|c|c|c|c|c|c|c|c|}
\hline \multirow[b]{2}{*}{ Quetelet's index $\left(\mathrm{kg} / \mathrm{m}^{2}\right)$} & \multicolumn{5}{|c|}{ Category } & \multirow[b]{2}{*}{$\chi^{*}$} & \multirow[b]{2}{*}{$p$} \\
\hline & $<23$ & $23-25$ & $26-28$ & $29-31$ & $\geq 32$ & & \\
\hline Cases $(n)$ & 1,002 & 939 & 579 & 391 & 364 & & \\
\hline Total $(n)$ & 30,660 & 16,102 & 6,081 & 3,167 & 2,208 & & \\
\hline Relative risk $\dagger$ & 1.0 & 1.67 & 2.80 & 3.86 & 5.70 & 32 & $<0.001$ \\
\hline $95 \%$ Confidence interval & & $(1.52-1.83)$ & $(2.50-3.13)$ & $(3.42-4.38)$ & $(4.99-6.49)$ & & \\
\hline Alcohol (g/day) & 0 & $0.1-9$ & $10-19$ & $20-29$ & $\geq 30$ & & \\
\hline Cases $(n)$ & 1,062 & 1,291 & 516 & 151 & 255 & & \\
\hline Total $(n)$ & 17,488 & 26,560 & 9,174 & 2,124 & 2,872 & & \\
\hline Relative risk $\dagger$ & 1.0 & 0.90 & 1.08 & 1.47 & 1.75 & 8.7 & $<0.001$ \\
\hline Relative risk $\ddagger$ & 1.0 & 0.92 & 1.13 & 1.47 & 1.70 & 8.0 & $<0.001$ \\
\hline $95 \%$ Confidence interval & & $(0.84-1.00)$ & $(1.01-1.26)$ & $(1.23-1.77)$ & $(1.46-1.98)$ & & \\
\hline
\end{tabular}

$* \chi$ values for test of trend.

$\lceil$ Model includes age, Quetelet's index, and alcohol consumption.

‡Model includes age, Quetelet’s index, alcohol consumption, and intakes of calcium, magnesium, potassium, and fiber. 
TABLE 2. Relative Risks of Hypertension by Level of Energy-Adjusted Daily Intake of Calcium, Magnesium, Potassium, and Fiber

\begin{tabular}{|c|c|c|c|c|c|c|c|}
\hline \multirow[b]{2}{*}{ Calcium (mg/day) } & \multicolumn{5}{|c|}{ Category } & \multirow[b]{2}{*}{$\chi^{*}$} & \multirow[b]{2}{*}{$p$} \\
\hline & $<400$ & $400-599$ & $600-799$ & $800-999$ & $\geq 1,000$ & & \\
\hline Cases $(n)$ & 436 & 1,047 & 911 & 458 & 423 & & \\
\hline Total $(n)$ & 6,671 & 17,664 & 16,522 & 9,134 & 8,227 & & \\
\hline Relative risk $\dagger$ & 1.0 & 0.90 & 0.83 & 0.77 & 0.79 & 3.8 & $<0.001$ \\
\hline Relative risk $\ddagger$ & 1.0 & 0.92 & 0.86 & 0.81 & 0.84 & 2.7 & 0.007 \\
\hline $95 \%$ Confidence interval & & $(0.82-1.05)$ & $(0.76-0.98)$ & $(0.70-0.94)$ & $(0.71-0.99)$ & & \\
\hline Magnesium (mg/day) & $<200$ & $200-249$ & $250-299$ & $300-349$ & $\geq 350$ & & \\
\hline Cases $(n)$ & 287 & 695 & 971 & 731 & 591 & & \\
\hline Total $(n)$ & 4,494 & 12,154 & 16,412 & 13,324 & 11,834 & & \\
\hline Relative risk $\dagger$ & 1.0 & 0.86 & 0.88 & 0.81 & 0.72 & 4.5 & $<0.001$ \\
\hline Relative risk $\ddagger$ & 1.0 & 0.91 & 0.93 & 0.85 & 0.78 & 2.2 & 0.03 \\
\hline $95 \%$ Confidence interval & & $(0.77-1.09)$ & $(0.77-1.12)$ & $(0.69-1.04)$ & $(0.62-0.98)$ & & \\
\hline Potassium (mg/day) & $<2,000$ & $2,000-2,399$ & $2,400-2,799$ & $2,800-3,199$ & $\geq 3200$ & & \\
\hline Cases $(n)$ & 395 & 704 & 945 & 705 & 526 & & \\
\hline Total $(n)$ & 6,190 & 12,672 & 16,466 & 12,624 & 10,266 & & \\
\hline Relative risk $\dagger$ & 1.0 & 0.86 & 0.89 & 0.85 & 0.77 & 3.3 & $<0.001$ \\
\hline Relative risk $\ddagger$ & 1.0 & 0.93 & 1.02 & 1.05 & 1.05 & 1.1 & 0.26 \\
\hline $95 \%$ Confidence interval & & $(0.80-1.00)$ & $(0.86-1.21)$ & $(0.87-1.27)$ & $(0.85-1.30)$ & & \\
\hline Fiber (g/day) & $<10$ & $10-14$ & $15-19$ & $20-24$ & $\geq 25$ & & \\
\hline Cases $(n)$ & 341 & 1,133 & 1,060 & 504 & 237 & & \\
\hline Total $(n)$ & 5,529 & 19,864 & 18,829 & 8,983 & 5,013 & & \\
\hline Relative risk $\dagger$ & 1.0 & 0.94 & 0.92 & 0.90 & 0.76 & 3.1 & 0.002 \\
\hline Relative risk $\ddagger$ & 1.0 & 0.97 & 0.98 & 0.99 & 0.87 & 1.5 & 0.14 \\
\hline 95\% Confidence interval & & $(0.85-1.11)$ & $(0.85-1.13)$ & $(0.84-1.16)$ & $(0.71-1.05)$ & & \\
\hline
\end{tabular}

${ }^{*} \chi$ values for test of trend.

$\lceil$ Model includes age, Quetelet's index, and alcohol consumption in addition to the specified nutrient.

$\ddagger$ Model includes age, Quetelet’s index, alcohol consumption, and intakes of calcium, magnesium, potassium, and fiber.

(see Table 5). Similar relations were found among younger and older women. Weaker associations, however, were observed among women with high relative weight. Menopausal status did not substantially alter the relations with dietary calcium and magnesium. The inverse association of calcium with hypertension was consistently seen among postmenopausal women, regardless of their use of estrogen supplements. An association of magnesium with hypertension, however, was not found among past or current users of postmenopausal estrogens. The relative risk of hypertension for women with high magnesium intake was lower among those who consumed over $20 \mathrm{~g}$ alcohol/day than among those with lower intakes.

We also examined associations of hypertension with calcium and magnesium intake expressed in relation to the Recommended Dietary Allowance (RDA) of these nutrients. For women with a calcium intake of at least the RDA of $800 \mathrm{mg} /$ day, the relative risk of hypertension was 0.78 (95\% confidence interval [CI] 0.69-0.88) compared with those in the lowest intake category (less than $400 \mathrm{mg} /$ day) after adjustment for age, Quetelet's index, and alcohol consumption. The adjusted relative risk for women above the RDA for magnesium intake of 300 $\mathrm{mg} /$ day was $0.77(95 \% \mathrm{CI}, 0.67-0.88)$ compared with those in the lowest intake category of magnesium $(<200 \mathrm{mg} /$ day). The adjusted relative risk of hypertension for women above the RDA for both calcium and magnesium intake $(n=11,248)$ compared with those in the lowest category for both nutrients $(n=2,003)$ was 0.65 (95\% CI, $0.53-0.80)$.

\section{Discussion}

Within this large cohort of women of whom $98 \%$ were white, we observed independent inverse associations for dietary calcium and magnesium with the incidence of hypertension. These associations remained after adjusting for age, relative weight, and alcohol consumption, each significantly contributing to the development of hypertension. Adjusting for calcium and magnesium intake eliminated the observed crude inverse associations of dietary potassium and fiber with risk of hypertension. No associations were observed for intakes of saturated fat and linoleic acid.

In this study, we relied on self-reported diagnoses of hypertension. Although a direct measurement is more objective, a single high blood pressure reading may not always represent hypertension because of the large within-person variability in measurements over time. ${ }^{21}$ The validity of diagnosis of hypertension in this study is supported by several lines of 
TABLE 3. Relative Risks of Hypertension by Level of Daily Intakes of Energy-Adjusted Fatty Acids

\begin{tabular}{|c|c|c|c|c|c|c|c|}
\hline \multirow{2}{*}{$\begin{array}{l}\text { Saturated fatty acids } \\
\text { (g/day) }\end{array}$} & \multicolumn{5}{|c|}{ Category } & \multirow[b]{2}{*}{$\chi^{*}$} & \multirow[b]{2}{*}{$p$} \\
\hline & $<20$ & $20-23$ & $24-27$ & $28-31$ & $\geq 32$ & & \\
\hline Relative risk $\dagger$ & 1.0 & 1.03 & 1.05 & 1.04 & 1.06 & 0.8 & 0.5 \\
\hline Relative risk $\ddagger$ & 1.0 & 1.01 & 1.02 & 0.99 & 0.99 & 0.4 & 0.7 \\
\hline $95 \%$ Confidence interval & & $(0.88-1.18)$ & $(0.89-1.18)$ & $(0.86-1.14)$ & $(0.86-1.16)$ & & \\
\hline Linoleic acid (g/day) & $<5.0$ & $5.0-7.4$ & $7.5-9.9$ & $10.0-12.4$ & $\geq 12.5$ & & \\
\hline Relative risk $\dagger$ & 1.0 & 1.0 & 0.99 & 1.05 & 1.03 & 0.4 & 0.7 \\
\hline Relative risk $\ddagger$ & 1.0 & 1.0 & 0.97 & 1.02 & 0.99 & 0.1 & 1.0 \\
\hline $95 \%$ Confidence interval & & $(0.89-1.11)$ & $(0.86-1.08)$ & $(0.89-1.18)$ & $(0.92-1.20)$ & & \\
\hline $\begin{array}{l}\text { Trans-unsaturated fatty } \\
\text { acids (g/day) }\end{array}$ & $<2.5$ & $2.5-3.4$ & $3.5-4.4$ & $4.5-5.4$ & $\geq 5.5$ & & \\
\hline Relative risk $\dagger$ & 1.0 & 1.22 & 1.20 & 1.16 & 1.24 & 1.4 & 0.2 \\
\hline Relative risk $\ddagger$ & 1.0 & 1.18 & 1.14 & 1.08 & 1.14 & 0.1 & 1.0 \\
\hline $95 \%$ Confidence interval & & $(1.02-1.36)$ & $(0.99-1.31)$ & $(0.92-1.25)$ & $(0.96-1.34)$ & & \\
\hline Total fat (g/day) & $<55$ & $55-64$ & $65-74$ & $75-84$ & $\geq 85$ & & \\
\hline Relative risk $\dagger$ & 1.0 & 1.04 & 1.04 & 1.03 & 1.05 & 0.4 & 0.7 \\
\hline Relative risk $\ddagger$ & 1.0 & 1.02 & 0.99 & 0.95 & 0.93 & 1.4 & 0.2 \\
\hline $95 \%$ Confidence interval & & $(0.90-1.15)$ & $(0.88-1.11)$ & $(0.83-1.08)$ & $(0.80-1.08)$ & & \\
\hline
\end{tabular}

${ }^{*} \chi$ values for test of trend.

†Model includes age, Quetelet's index, and alcohol consumption.

$\$$ Model includes intakes of calcium and magnesium in addition to age, Quetelet’s index, and alcohol consumption.

evidence. First, the accuracy of the measure was shown in a subsample. ${ }^{20}$ Second, the age-specific incidence rates of hypertension were nearly identical to those observed in the Framingham study. ${ }^{22}$ Third, a strong association between self-reported hypertension and risk of myocardial infarction has been observed prospectively in the Nurses' Health Study. ${ }^{23}$ Furthermore, detection bias is likely to be minimal in this analysis because women who subsequently developed hypertension and those who remained normotensive had a similar frequency of doctor visits as reported on the 1978 questionnaire.

Although comparison of the questionnaire data with those from dietary records indicated a reasonable level of validity, ${ }^{17-19}$ our measure of diet was certainly not perfect. Because diet was measured before diagnosis, it is reasonable to assume that associations were relatively unbiased with respect to hypertension status; in the event that knowledge of borderline hypertension might have caused women

TABLE 4. Relative Risks of Hypertension by Level of Daily Calcium and Magnesium Intakes From Different Food Sources*

\begin{tabular}{|c|c|c|c|c|c|c|c|}
\hline \multirow[b]{2}{*}{ Calcium (mg/day) } & \multicolumn{5}{|c|}{ Category } & \multirow[b]{2}{*}{$\chi^{\dagger}$} & \multirow[b]{2}{*}{$p$} \\
\hline & $<200$ & $200-299$ & $300-399$ & $400-499$ & $\geq 500$ & & \\
\hline Dairy & 1.0 & $\begin{array}{c}0.96 \\
(0.85-1.07)\end{array}$ & $\begin{array}{c}0.95 \\
(0.85-1.06)\end{array}$ & $\begin{array}{c}0.91 \\
(0.81-1.03)\end{array}$ & $\begin{array}{c}0.85 \\
(0.77-0.93)\end{array}$ & 3.3 & 0.001 \\
\hline Nondairy & 1.0 & $\begin{array}{c}0.95 \\
(0.86-1.05)\end{array}$ & $\begin{array}{c}0.94 \\
(0.84-1.06)\end{array}$ & $\begin{array}{c}0.85 \\
(0.73-0.98)\end{array}$ & $\begin{array}{c}0.80 \\
(0.64-0.98)\end{array}$ & 2.6 & 0.009 \\
\hline Magnesium (mg/day) & $<30$ & $30-39$ & $40-49$ & $50-59$ & $\geq 60$ & & \\
\hline Fruits and vegetables & 1.0 & $\begin{array}{c}0.98 \\
(0.82-1.25)\end{array}$ & $\begin{array}{c}0.87 \\
(0.72-1.06)\end{array}$ & $\begin{array}{c}0.81 \\
(0.66-0.98)\end{array}$ & $\begin{array}{c}0.88 \\
(0.74-1.05)\end{array}$ & 1.0 & 0.33 \\
\hline Cereals & 1.0 & $\begin{array}{c}0.91 \\
(0.82-1.01)\end{array}$ & $\begin{array}{c}0.91 \\
(0.80-1.02)\end{array}$ & $\begin{array}{c}0.96 \\
(0.83-1.11)\end{array}$ & $\begin{array}{c}0.88 \\
(0.80-0.96)\end{array}$ & 2.5 & 0.011 \\
\hline Dairy & 1.0 & $\begin{array}{c}1.0 \\
(0.90-1.11) \\
\end{array}$ & $\begin{array}{c}0.95 \\
(0.85-1.08)\end{array}$ & $\begin{array}{c}0.87 \\
(0.75-1.00)\end{array}$ & $\begin{array}{c}0.86 \\
(0.78-0.95) \\
\end{array}$ & 3.1 & 0.002 \\
\hline $\begin{array}{l}\text { Magnesium other } \\
\text { (mg/day) }\end{array}$ & $<100$ & $100-124$ & $125-149$ & $150-174$ & $\geq 175$ & & \\
\hline & 1.0 & $\begin{array}{c}1.0 \\
(0.90-1.10)\end{array}$ & $\begin{array}{c}0.92 \\
(0.83-1.03)\end{array}$ & $\begin{array}{c}0.96 \\
(0.85-1.08)\end{array}$ & $\begin{array}{c}0.82 \\
(0.72-0.92)\end{array}$ & 3.2 & 0.002 \\
\hline
\end{tabular}

\footnotetext{
*Model includes age, Quetelet's index, alcohol consumption, and intakes of calcium and magnesium from other food sources; $95 \%$
} confidence intervals are in parentheses.

$\dagger \chi$ values for test of trend. 
TABLE 5. Relative Risks of Hypertension by Level of Daily Calcium and Magnesium Intake, Within Strata of Other Variables*

\begin{tabular}{|c|c|c|c|c|c|c|c|}
\hline \multirow[b]{2}{*}{ Risk } & \multirow[b]{2}{*}{$n$} & \multicolumn{3}{|c|}{ Calcium (mg) } & \multicolumn{3}{|c|}{ Magnesium (mg) } \\
\hline & & $<400$ & $400-799$ & $\geq 800$ & $<200$ & $200-299$ & $\geq 300$ \\
\hline \multicolumn{8}{|l|}{ Age (yr) } \\
\hline$<=44$ & 27,038 & 1.0 & 0.88 & $0.79 \ddagger$ & 1.0 & 0.86 & 0.81 \\
\hline$>45$ & 31,180 & 1.0 & 0.86 & 0.78 利 & 1.0 & 0.88 & $0.75 \ddagger \|$ \\
\hline \multicolumn{8}{|c|}{$\begin{array}{l}\text { Quetelet's index } \\
\left(\mathrm{kg} / \mathrm{m}^{2}\right)\end{array}$} \\
\hline$<23$ & 30,660 & 1.0 & 0.84 & $0.77 \ddagger \S$ & 1.0 & $0.67 \S$ & $0.62 \ddagger \|$ \\
\hline $23-28$ & 22,183 & 1.0 & 0.88 & $0.72 \ddagger \S$ & 1.0 & 0.90 & $0.78 \ddagger \S$ \\
\hline$\geq 29$ & 5,375 & 1.0 & 0.87 & 0.94 & 1.0 & 1.15 & 0.92 \\
\hline \multicolumn{8}{|c|}{ Menopausal status $\dagger$} \\
\hline Before & 33,995 & 1.0 & 0.89 & $0.75 \ddagger \S$ & 1.0 & $0.84 \S$ & $0.77 \ddagger \|$ \\
\hline After & 23,607 & 1.0 & 0.84 & $0.80 \div \S$ & 1.0 & 0.92 & $0.77 \ddagger \S$ \\
\hline \multicolumn{8}{|c|}{$\begin{array}{l}\text { Postmenopausal } \\
\text { hormone use }\end{array}$} \\
\hline Never & 13,859 & 1.0 & 0.81 & 0.80 & 1.0 & 0.78 & $0.66 \ddagger \S$ \\
\hline Past & 5,320 & 1.0 & 0.82 & 0.80 & 1.0 & 1.20 & 0.99 \\
\hline Current & 4,428 & 1.0 & 0.94 & 0.78 & 1.0 & 1.13 & 0.96 \\
\hline \multicolumn{8}{|c|}{ Alcohol use (g/day) } \\
\hline$<0.1$ & 17,488 & 1.0 & 0.94 & $0.78 \ddagger \S$ & 1.0 & 0.92 & $0.81 \ddagger$ \\
\hline $0.1-19$ & 35,488 & 1.0 & $0.82 \S$ & $0.76 \ddagger \S$ & 1.0 & 0.91 & $0.77 \ddagger \S$ \\
\hline$\geq 20$ & 4,996 & 1.0 & 0.81 & 0.79 & 1.0 & $0.60 \S$ & $0.62 \S$ \\
\hline
\end{tabular}

*Model includes age, Quetelet's Index, and alcohol consumption (except for data stratified by alcohol intake). †Missing data on menopause for 616 women.

$\ddagger$ Significant trend $(p \leq 0.05) ; \S p<0.05$ for relative risk; $\| p<0.01$ for relative risk.

to change their diets, the direction of any change would have been more likely to obscure relations with calcium and magnesium than to create them. For these reasons, the strength of observed associations probably represents an underestimation of the true effects of diet. We did not attempt to measure salt intake in this study; however, a relation between salt intake and hypertension has usually not been found in studies within populations as reviewed elsewhere. ${ }^{1}$ In a recent report from the INTERSALT study, ${ }^{24}$ no significant association was seen between diastolic blood pressure and urinary sodium excretion, and only a $1.6-\mathrm{mm} \mathrm{Hg}$ change in systolic pressure per $100 \mathrm{mmol} \mathrm{Na}$ was found (100 mmol approximately corresponding to the difference between the average US daily excretion and that of isolated primitive populations in Africa and South America). Because the associations between sodium intake and calcium and magnesium intakes are also not likely to be strong (these correlations were both less than 0.05 after adjustment for total caloric intake based on the mean of four 1-week diet records provided by a sample of 173 women in our population), sodium intake could not seriously distort the relations we observed.

Several cross-sectional studies of the relation between calcium intake and blood pressure have recently been published. McCarron et $\mathrm{al}^{3}$ reported an inverse association of dietary calcium with blood pressure in the National Health and Nutrition Examination Survey (NHANES) I study, but a reanalysis of the NHANES I and the NHANES II investiga- tions did not find such an association ${ }^{25}$; a major limitation of the NHANES studies is that diet was assessed with a single 24-hour recall. Other various large-scale epidemiologic studies support the existence of an association of blood pressure with either total dietary calcium $6,12,13$ or calcium from dairy products. 4,26,27 In trials of calcium supplement administration, blood pressure was reduced in subjects with mild ${ }^{28}$ or more severe hypertension, ${ }^{29,30}$ although in some studies this was observed for only a subset of the population. ${ }^{28}$ No effect of calcium supplementation on blood pressure has been found among normotensive subjects in several studies ${ }^{29-31}$; however, Lyle et $\mathrm{al}^{32}$ have reported a modest reduction among normotensive men supplemented with $1,500 \mathrm{mg} \mathrm{Ca} /$ day.

The relation of dietary magnesium with hypertension has been examined in only a few studies. In a recent analysis of data from the Honolulu Heart Study, ${ }^{14}$ a low magnesium intake was found to be the dietary factor most strongly associated with high blood pressure. In two small case-control studies, no associations were observed, ${ }^{33,34}$ although an inverse trend was seen in one. ${ }^{33}$ The response to short-term supplementation of magnesium, however, may be different from that related to long-term dietary intake, which may inhibit a gradual rise in blood pressure over many years. A blood pressurelowering effect of magnesium supplementation in hypertensive subjects receiving diuretic treatment has been observed, ${ }^{35}$ but this could not be con- 
firmed in another intervention study ${ }^{36}$ or in a shortterm trial among untreated hypertensive subjects. ${ }^{37}$

A protective effect of potassium has been found in several cross-sectional studies, ${ }^{2-4,24}$ but no association has been observed in some others. ${ }^{5,6} \mathrm{~A}$ reduction in blood pressure has been shown in one trial of potassium administration ${ }^{7}$ but not in another. ${ }^{8}$ An association between fiber and blood pressure could not be shown in several intervention studies testing different types of fiber. ${ }^{38-40}$ In contrast, an effect has been suggested by another intervention study ${ }^{41}$ and one observational study. ${ }^{14}$ None of these studies, however, controlled for the intake of minerals.

An inverse relation of blood pressure with a high ratio of dietary polyunsaturated fatty acids to saturated fatty acids has been found in some intervention trials ${ }^{10,42}$ and in one observational study ${ }^{12}$ but not in others. ${ }^{3,11,14}$ No effect was observed in all double-blind trials ${ }^{43-45}$ and in most of the unblinded studies. ${ }^{38,46}$ To our knowledge, no studies have been reported that examined the relation of transunsaturated fatty acids with blood pressure in humans.

We examined the possibility that other variables might modify the observed associations of calcium and magnesium intake with hypertension. The effects of both nutrients were less among women in the highest category of Quetelet's index. No effect was shown for magnesium among past or present users of postmenopausal hormones, which might be due to estrogen-induced magnesium retention. ${ }^{47} \mathrm{~A}$ particularly strong effect of magnesium was observed among subjects in the highest category of alcohol intake, perhaps because alcohol consumption increases urinary excretion of magnesium. ${ }^{48}$ The finding of independent associations of calcium and magnesium from different food sources provides support that the observed effects are due to these nutrients themselves, rather than being mediated by some other factor in specific foods.

In summary, high relative weight and alcohol consumption were the strongest predictors of hypertension, and our data support the existing public health recommendations for control of these factors. ${ }^{49}$ Compared with the adverse impact of overweight and alcohol intake, the protective effects of dietary calcium and magnesium were modest. However, as pointed out by Rose, 50 even a small reduction in the average blood pressure of a population can result in major reduction in complications. The presence of significant trends and the existence of plausible mechanisms of action $28,32,51,52$ indicate the need for further clinical trials to determine whether or not the observed associations between intakes of calcium and magnesium and blood pressure are causal. Such trials should also address previous suggestions that other metabolic factors may influence susceptibility to the effects of low calcium and magnesium intake. A large portion of our study population consumed less than the
RDA of calcium and magnesium and thus could potentially benefit from a higher intake of these nutrients. However, the relative advantages of increasing intake by changes in diet or by supplementation need to be carefully considered as would the possible long-term consequences for other important health-related outcomes.

\section{Acknowledgments}

We are grateful to the nurse participants and for the help of David Dysert, Barbara Egan, Meryl Dannenberg, Karen Corsano, Pradip Rana, Roberta Anderson, Laura Sampson, and Marion McPhee.

\section{References}

1. Meneely GR, Battarbee HD: High sodium-low potassium environment and hypertension. Am J Cardiol 1976;38:768-785

2. Khaw KT, Barrett-Connor E: Dietary potassium and blood pressure in a population. Am J Clin Nutr 1984;39:963-968

3. McCarron DA, Morris CD, Henry HJ, et al: Blood pressure and nutrient intake in the United States. Science 1984; 224:1392-1398

4. Reed D, McGee D, Yano D, et al: Diet, blood pressure, and multicollinearity. Hypertension 1985;7:405-410

5. Harlan WR, Hull AL, Schmouder RL, et al: Blood pressure and nutrition in adults. Am J Epidemiol 1984;120:17-27

6. Kok FJ, Vandenbroucke JP, Heide-Wessel van der C, et al: Dietary sodium, calcium, and potassium, and blood pressure. Am J Epidemiol 1986;123:1043-1048

7. MacGregor GA, Smith SJ, Markandu ND, et al: Moderate potassium supplementation in essential hypertension. Lancet 1982;2:567-570

8. Richards AM, Nicholls MG, Espiner EA: Blood-pressure response to moderate sodium restriction and to potassium supplementation in mild essential hypertension. Lancet 1984; 1:757-761

9. Wright A, Burstyn PG, Gibney MJ: Dietary fibre and blood pressure. Br Med J 1979;2:1541-1543

10. Iacono JM, Judd T, Marshall MW, et al: The role of dietary essential fatty acids and prostaglandins in reducing blood pressure. Prog Lipid Res 1981;20:349-364

11. Gruchow HW, Sobocinski KA, Barboriak JJ: Alcohol, nutrient intake, and hypertension in US adults. JAMA 1985; 253:1567-1570

12. Nichaman M, Shekelle R, Paul O: Diet, alcohol, and blood pressure in the Western Electric Study (abstract). Am J Epidemiol 1984;120:469-470

13. Kromhout D, Bosschieter EB, Lezenne Coulander de C: Potassium, calcium, alcohol intake and blood pressure: The Zutphen Study. Am J Clin Nutr 1985;41:1299-1304

14. Joffres MR, Reed DM, Yano K: Relationship of magnesium intake and other dietary factors to blood pressure: The Honolulu heart study. Am J Clin Nutr 1987;45:469-475

15. Beaton GH, Milner J, Corey P: Sources of variance in 24-hour dietary recall data: Implications for nutrition study design and interpretation. Am J Clin Nutr 1979;32:2456-2559

16. Willett WC, Stampfer MJ, Colditz GA, et al: Dietary fat and the risk of breast cancer. $N$ Engl J Med 1987;316:22-28

17. Willett WC, Sampson L, Stampfer MJ, et al: Reproducibility and validity of a semiquantitative food frequency questionnaire. Am J Epidemiol 1985;122:51-65

18. Willett WC, Reynolds RO, Cottrell-Hoehner S, Sampson L, Browne ML: Comparison of a semiquantitative foodfrequency questionnaire with a one-year diet record. $J \mathrm{Am}$ Diet Assoc 1987;87:43-47

19. Willett WC, Sampson L, Browne ML, Stampfer MJ, Rosner B, Hennekens $\mathrm{CH}$, Speizer FE: The use of a selfadministered questionnaire to assess diet four years in the past. Am J Epidemiol 1988;127:188-199

20. Colditz GA, Martin P, Stampfer MJ, et al: Validation of questionnaire information on risk factors and disease out- 
comes in a prospective cohort study of women. Am J Epidemiol 1986;123:894-900

21. Rosner B, Polk BF: Predictive values of routine blood pressure measurements in screening for hypertension. Am J Epidemiol 1983;117:429-442

22. Dannenberg AL, Garrison RJ, Kannel WB: Incidence of hypertension in the Framingham Study. Am J Public Health 1988;78:676-679

23. Willett WC, Green A, Stampfer MJ, et al: Relative and absolute excess risks of coronary heart disease among women who smoke cigarettes. $N$ Engl J Med 1987; 19:1303-1309

24. Intersalt Cooperative Research Group: Intersalt: An international study of electrolyte excretion and blood pressure: Results for 24-hour urinary sodium and potassium excretion. Br Med J 1988;297:319-328

25. Sempos C, Cooper R, Kovar MG, et al: Dietary calcium and blood pressure in National Health and Nutrition Examination Surveys I and II. Hypertension 1986;8:1067-1074

26. Garcia-Palmieri MR, Costas R, Cruz-Vidal M: Milk consumption, calcium intake, and decreased hypertension in Puerto Rico. Hypertension 1984;6:322-328

27. Ackley S, Barrett-Conner E, Suarez L: Dairy products, calcium, and blood pressure. Am J Clin Nutr 1983;38:457-461

28. Grobbee DE, Hofman A: Effect of calcium supplementation on diastolic blood pressure in young people with mild hypertension. Lancet 1986;2:703-707

29. McCarron DA, Morris CD: Blood pressure response to oral calcium in persons with mild to moderate hypertension. Ann Intern Med 1985;103:825-831

30. Johnson NE, Smith EL, Freudenheim JL: Effects on blood pressure of calcium supplementation of women. Am J Clin Nutr 1985;42:12-17

31. Beresteyn van ECH, Schaafsma G, Waard de H: Oral calcium and blood pressure: A controlled intervention trial. Am J Clin Nutr 1986;44:883-888

32. Lyle R, Melby CL, Hyner GC, Edmondson JW, Miller JZ, Weinberger MH: Blood pressure and metabolic effects of calcium supplementation in normotensive white and black men. JAMA 1987;257:1772-1776

33. McCarron DA: Calcium and magnesium nutrition in human hypertension. Ann Intern Med 1983;98(part 2):800-805

34. Thulin T, Dencker AI, Jagerstad M, et al: Comparison of energy and nutrient intakes in women with high and low blood pressure levels. Acta Med Scand 1980;208:367-373

35. Dyckner T, Wester PO: Effect of magnesium on blood pressure. Br Med J 1983;286:1847-1849

36. Henderson DG, Schierup J, Schodt T: Effect of magnesium supplementation on blood pressure and electrolyte concentrations in hypertensive patients receiving long term diuretic treatment. Br Med J 1986;293:664-665

37. Cappuccio FP, Markandu ND, Beynon GW, et al: Lack of effect of oral magnesium on high blood pressure: A double blind study. Br Med $J$ 1985;291:235-238

38. Brussaard JH, Raaij van JMA, Stasse-Wolthuis M, et al: Blood pressure and diet in normotensive volunteers: Absence of an effect of dietary fiber, protein, or fat. Am J Clin Nutr 1981;34:2023-2029

39. Margetts BM, Beiliu LJ, Vandongen R, Armstrong BK: A randomized trial of the effect of dietary fibre on blood pressure. Clin Sci 1987;72:343-350

40. Kelsay J, Behall K, Prather E: Effect of fiber from fruits and vegetables on metabolic responses of human subjects: 1 . Bowel transit time, number of defecations, fecal weight, urinary excretion of energy and nitrogen, and apparent digestibilities of energy, nitrogen, and fat. Am J Clin Nutr 1978;31:1149-1153

41. Anderson JW: Plant fiber and blood pressure. Ann Intern Med 1983;98(part 2):842-846

42. Puska P, Iacono JM, Nissinen A, et al: Controlled, randomised trial of the effect of dietary fat on blood pressure. Lancet 1983;1:1-5

43. Sacks FM, Rouse IA, Stampfer MJ, Bishop LM, Lenherr $\mathrm{CF}$, Walther RJ: Effect of dietary fats and carbohydrate on blood pressure of mildly hypertensive patients. Hypertension 1987;10:452-460

44. Sacks FM, Stampfer MJ, Munoz A, McManus K, Canessa M, Kass EH: Effect of linoleic and oleic acids on blood pressure, blood viscosity, and erythrocyte cation transport. J Am Coll Nutr 1987;6:179-185

45. Margetts BM, Beilin LJ, Armstrong BK, et al: Blood pressure and dietary polyunsaturated and saturated fats: A controlled trial. Clin Sci 1985;69:165-175

46. Sacks FM, Marais GE, Handysides G, et al: Lack of an effect of dietary saturated fat and cholesterol on blood pressure in normotensives. Hypertension 1984;6:193-198

47. Seelig MS, Lehr D: Effects of estrogen on tissue magnesium content: Possible influence on cardiovascular and bone disease, in Durlach $\mathbf{J}$ (ed): Symposium International sur le Deficit Magnesique en Pathologie Humaine. Vittel, 9-15 Mai 1971. Volume des Rapports (S.G.E.M.V.), 1973, pp 249-255

48. Kalbfleisch JM, Lindeman RD, Ginn HE, et al: Effects of ethanol administration on urinary excretion of magnesium and other electrolytes in alcoholic and normal subjects. $J$ Clin Invest 1963;42:1471-1475

49. Hennekens CH. Alcohol, in Kaplan NM, Stamler J (eds): Prevention of Coronary Heart Disease; Practical Management of the Risk Factors. Philadelphia, WB Saunders, 1983, pp 130-138

50. Rose G: Strategy of prevention: Lessons from cardiovascular disease. Br Med J 1981;282:1847-1851

51. Haddy FJ, Seelig MS: Magnesium and the arteries: II. Physiologic effects of electrolyte abnormalities on arterial resistance, in Cantin M, Seelig MS (eds): Proceedings of the 2nd International Symposium on Magnesium, Montreal, Quebec 1976. New York/London, Spectrum Publications, 1980 , pp 639-657

52. Resnick LM: Uniformity and diversity of calcium metabolism in hypertension. Am J Med 1987;82(suppl B):16-26

KEY WordS • diet $\cdot$ nutrition $\cdot$ hypertension $\cdot$ calcium $•$ magnesium 